\title{
EFFECTIVENESS OF FUNCTIONAL ENDOSCOPIC SINUS SURGERY IN SINONASAL POLYPOSIS AND CO- EXISTING ASTHMA, MEASURED BY PRE- \& POSTOPERATIVE SPIROMETRY
}

\author{
Shibu George ${ }^{1}$ Roshith Nair ${ }^{2}$ \\ ${ }^{1}$ Additional Professor, Department of ENT, Government Medical College, Trivandrum. \\ 'Junior Consultant, Department of ENT, Government Hospital, Nadapuram, Calicut.
}

\section{ABSTRACT}

\section{BACKGROUND}

Nasal polyposis is a disease known to have significant association with asthma. The first-line management is clearly anti-inflammatory, with topical and oral corticosteroids. Endoscopic sinus surgery is indicated in polyps resistant to steroids and improves nasal resistance; this should benefit patients with co-existing asthma by reduction in pulmonary resistance.

\section{MATERIALS AND METHODS}

This was a prospective 2-year study of 50 patients with asthma and nasal polyposis, on the benefits of functional endoscopic sinus surgery (FESS) on the lower airway parameters which includes forced expiratory volume (FEV1) and forced vital capacity (FVC) and forced expiratory ratio (FER) as measured by spirometry.

\section{RESULTS}

There was clinically and statistically significant mean increment in FEV1 $(\mathrm{p}=0.01)$, FVC $(\mathrm{p}=0.018)$ and FER (P=0.02). Significant improvement in PFT was noted in children and patients with allergic rhinitis while patients with Samter's triad demonstrated marginal improvement.

\section{CONCLUSION}

Functional endoscopic sinus surgery effects a small but significant improvement in lung function as evidenced by pre-and postoperative spirometric measures and could be considered early in the natural course of nasal polyposis with concomitant asthma.

\section{KEYWORDS}

Nasal Polyps, Asthma, Endoscopic Surgery, Spirometry, Allergic Rhinitis.

HOW TO CITE THIS ARTICLE: George S, Nair R. Effectiveness of functional endoscopic sinus surgery in sinonasal polyposis and co-existing asthma, measured by pre- \& postoperative spirometry. J. Evolution Med. Dent. Sci. 2017;6(3):150-154, DOI: $10.14260 /$ Jemds/2017/37

\section{BACKGROUND}

The link between upper and lower airway had led to the concept of 'allergic rhinitis' and its impact on asthma (ARIA) or unified airway.[1] This concept primarily refers to the wellestablished link between allergic rhinitis and asthma, but it also covers a possible link between sinus disease, asthma and other lower airway disease.[2,3,4,5,6] Successful treatment of nasal polyposis becomes irrelevant if an unrecognised asthma threatens a patient's quality and longevity of life.[7,8,9] So, it is essential for an otorhinolaryngologist to have a better understanding about the dynamics of the lower airway and how close it is linked physiologically to the sinonasal passages. Functional endoscopic sinus surgery (FESS) is a minimally invasive technique that uses an endoscope to operate on the sinonasal outflow to improve sinus ventilation and drainage.[10,11,12,13] Improvement in nasal resistance should benefit patients with co-existing asthma by reduction in pulmonary resistance and lower airway inflammation. ${ }^{[14,15,16,17]}$ A comprehensive way of recognition

Financial or Other, Competing Interest: None.

Submission 19-12-2016, Peer Review 31-12-2016,

Acceptance 02-01-2017, Published 07-01-2017.

Corresponding Author:

Shibu George,

Charivukalayil, Ettumanoor (P.O.),

Kottayam-686631,

Kerala.

E-mail: drshibugeorge@gmail.com

DOI: $10.14260 /$ jemds $/ 2017 / 37$ and management of the two links to upper and lower airway thus should lead to improvement in overall patient outcome and physical quality of life. This study aims at analysis of the effectiveness of FESS for asthmatics with nasal polyps in improving the lower airway resistance as measured by pulmonary function parameters during spirometry.

\section{MATERIALS AND METHODS}

A prospective study was conducted in the Department of Otorhinolaryngology Medical College, Kottayam between November 2009 to December 2011 after obtaining necessary clearance from the institutional review board and informed consent from the patient (from parent if minor).

\section{Inclusion Criteria}

Patients diagnosed with refractory sino-nasal polyposis not responding to medical management with systemic and topical steroids for a minimum period of 12 weeks and having coexisting bronchial asthma were included in the study.

\section{Exclusion Criteria}

Patients with history of wheeze but normal pulmonary function parameters during spirometry were excluded. Patients with sino-nasal polyposis having pulmonary diseases other than asthma like interstitial lung diseases or cystic fibrosis were also excluded.

A pre-operative diagnostic nasal endoscopy and CT scan of the nose and paranasal sinuses were done in all patients to evaluate the extent of the disease. A prior confirmation of diagnosis of asthma was made both clinically as well as by 
pulmonary function tests (PFT) using spirometry. During spirometry $\mathrm{FEV} 1 / \mathrm{FVC}$ ratio $<70 \%$ and increase in FEV1 by $12 \%$ and $200 \mathrm{~mL}$, following bronchodilator therapy was taken as significant. Endoscopic sinus surgery was done preferably under monitored local anaesthesia (general anaesthesia in children and apprehensive adults). Patients were reviewed after 3 months and 6 months when postprocedure pulmonary status was assessed along with repeating PFT. Observations were tabulated as per standard scoring system.

\section{Statistical Analysis}

Results were analysed using paired $t$ test, independent $t$ test \& ANOVA using SPSS version 16. P value less than 0.05 was taken as significant.

\section{RESULTS}

Out of 50 patients, 28 (56\%) were male and 22 (44\%) female.

Maximum numbers of patients were between age of 30 and 45 years. Mean age of the subjects was 36.7 years with a $95 \%$ confidence interval of $+/-12.3$.

Allergic rhinitis was the most frequent comorbid factor (82\%). 24\% had hypertension, $28 \%$ had diabetes mellitus and 6 patients had both.

17 patients $(66 \%)$ were smokers (Table 1$)$.

28 patients $(56 \%)$ had history of childhood asthma and 27 patients (54\%) had history of frequent hospitalisations.

6 out of 50 patients $(12 \%)$ had a history suggestive of Samter's triad.

Before surgery most of the patients had five to ten attacks of asthma within a period of 6 months.

Pulmonary function test before surgery showed mean FEV1 of 2.15 +/- 0.42 litres, mean FVC 3.16+/- 0.61 litres and the mean FER (FEV1/FVC) was $68.12 \%+/-1.5$. Followup PFT was done after 3 and 6 months after surgery.

Analysis at 6 months showed that there was clinically and statistically significant mean increment of $140-150 \mathrm{~mL}$ and 85-90 mL in FEV1 ( $\mathrm{p}=0.01)$ and FVC $(\mathrm{p}=0.018)$ respectively. Improvement in FER was about $2.5-2.6 \%(\mathrm{P}=0.02)$ (Table 2).

Following surgery frequency of asthmatic attacks monitored for six months showed significant reduction with $44 \%$ patients reporting less than 5 attacks. On enquiry about subjective improvement $56 \%$ gave a "definitely yes" response while for $16 \%$ it was "definitely no" (Table 3 ).

There was statistically significant improvement $(p<0.05)$ in pulmonary function among younger age group as compared to older patients; maximum improvement was noted among patients < 15 years. There was significantly improved FVC in patients with childhood asthma, within a short span post-operatively.

Improvement in FEV1 were observed to be slightly better in females but was not statistically significant $(\mathrm{p}=0.4)$

There was no significant difference in PFT values in patients with associated comorbidities like diabetes mellitus and hypertension.

Though there was an increment of FVC among nonsmokers as compared to smokers it was not statistically significant $(\mathrm{p}=0.100)$.

Patients with allergic rhinitis had significant improvement in FEV1 $(\mathrm{p}=0.02)$ and FVC $(\mathrm{p}=0.04)$ after surgery.

Patients with NSAID intolerance showed no significant improvement in FEV1 $(\mathrm{P}=0.5)$ post-operatively; but FVC values demonstrated improvement and that could be statistically supported $(\mathrm{p}=0.01)$. (Table 4$)$

\begin{tabular}{|c|c|c|c|c|c|c|}
\hline Age Group & Males & Females & Allergic Rhinitis & Hypertension & Diabetes Mellitus & NSAID intolerance \\
\hline $0-15$ & 2 & 1 & 3 & 0 & 0 & 0 \\
\hline $16-30$ & 6 & 6 & 10 & 1 & 0 & 1 \\
\hline $31-45$ & 13 & 9 & 19 & 4 & 4 & 4 \\
\hline $45-60$ & 6 & 5 & 8 & 5 & 9 & 1 \\
\hline$>60$ & 1 & 1 & 1 & 2 & 1 & 0 \\
\hline Total & $\mathbf{2 8}$ & $\mathbf{2 2}$ & $\mathbf{4 1}$ & $\mathbf{1 2}$ & $\mathbf{1 4}$ & $\mathbf{6}$ \\
\hline \multicolumn{7}{|c|}{ Table 1. Age, Sex \& Associations/Comorbidities among Study Population (n=50) } \\
\hline
\end{tabular}

\begin{tabular}{|c|c|c|c|}
\hline PFT & $\begin{array}{c}\text { Pre- } \\
\text { Operative }\end{array}$ & $\begin{array}{c}\text { Post-Op 3 } \\
\text { months }\end{array}$ & $\begin{array}{c}\text { Post-Op 6 } \\
\text { months }\end{array}$ \\
\hline FEV1 (Litres) & $2.153+/-$ & $2.291+/-$ & $2.297+/-0.377$ \\
& 0.425 & 0.383 & \\
\hline \multirow{2}{*}{ FVC (Litres) } & $3.155+/-$ & $3.239+/-$ & $3.243+/-0.524$ \\
& 0.608 & 0.529 & $70.698+/-$ \\
\hline FEV1/FVC & $68.12+/-$ & $70.724+/-3.184$ \\
(\%) & 1.459 & 3.107 & \\
\hline \multicolumn{4}{|c|}{ Table 2. Comparison of Mean PFT Values before and after } \\
\hline
\end{tabular}

\begin{tabular}{|c|c|c|c|c|c|c|}
\hline $\begin{array}{c}\text { PFT } \\
\text { (6 months } \\
\text { Post-op) }\end{array}$ & Males & Females & Smokers & $\begin{array}{c}\text { Non- } \\
\text { Smokers }\end{array}$ & $\begin{array}{l}\text { Allergic } \\
\text { Rhinitis }\end{array}$ & $\begin{array}{c}\text { Samter's } \\
\text { Triad }\end{array}$ \\
\hline $\begin{array}{c}\text { Mean } \\
\text { Difference } \\
\text { in FEV1 }\end{array}$ & $\begin{array}{c}0.126 \\
+/- \\
0.179 \\
\end{array}$ & $\begin{array}{c}0.166+/- \\
0.201\end{array}$ & $\begin{array}{c}0.084+/- \\
0.106\end{array}$ & $\begin{array}{c}0.174+/- \\
0.214\end{array}$ & $\begin{array}{c}0.163+/ \\
0.198\end{array}$ & $-0.205+/-$ \\
\hline $\begin{array}{c}\text { Mean } \\
\text { Difference } \\
\text { in FVC } \\
\end{array}$ & $\begin{array}{c}0.069 \\
+/- \\
0.227 \\
\end{array}$ & $\begin{array}{c}0.111+/- \\
0.285\end{array}$ & $\begin{array}{c}0.034+/- \\
0.106\end{array}$ & $\begin{array}{c}0.115+/- \\
0.299\end{array}$ & $0.106+/$ & $-0.318+/-$ \\
\hline
\end{tabular}

\section{DISCUSSION}

In ancient Greece, Galenus was the first physician to recognise the link between nose and lung. The link between upper airway and lower airway is well established and had led to the concept of "Allergic rhinitis and its impact on asthma" (ARIA).[1] 
Asthma, allergy and rhinosinusitis appear to behave similarly; according to the concept of unified airway model, the entire respiratory system represents a functional unit that consists of nose, paranasal, sinuses, larynx, trachea and distal lung. The broad number of inflammatory diseases that occur within this functional unit present to a variety of specialities including otolaryngology, pulmonology, primary care and allergy. The classic paper, the Finnish Twin Cohort Study, more than 11,000 patients were followed longitudinally to assess whether the presence of allergic rhinitis was associated with the development of other respiratory diseases over time. Similar relationships have been identified among other allergic and non-allergic respiratory diseases. [2,3] The concept of asthma as a chronic inflammatory disease emerged thus shifting the pathophysiological focus of asthma from bronchospasm to one of inflammation that is mediated at the cellular level. Several mechanisms have been postulated to explain the observed relationship between diseases of upper and lower airway. Three potential mechanisms include:

- The Nasobronchial reflex: Argument for the presence of nasobronchial reflex dates back almost a century when Sluder proposed that nasal irritation could cause bronchospasm, leading to the development of bronchial asthma. Primary study providing support for this mechanism was conducted by Kaufman and Wright.[4]

- Loss of nasal protection of the lower airway: Studies to support this hypothesis was reported by ShturmanEllstein and colleagues in 1978.[5] In this trial patients who had exercise-induced asthma were allowed to exercise under three conditions - spontaneous breathing, nasal breathing and mouth breathing. The result of this study demonstrated that mouth breathing worsened bronchospasm, while nasal breathing appeared to have a protective effect. Hence, nasal breathing has been found to have a beneficial effect on the lower airway through conditioning inspired air for delivery to the lungs.

- Shared inflammations: The respiratory mucosa in the middle ear, nose, sinuses and lower respiratory tract is structurally and physiologically uniform, having a pseudostratified columnar epithelium that is involved in active transport of mucous and particulate matter. Studies by Braunstahl and colleagues have shown that stimulation of one portion of airway mucosa with antigen will result in system wide inflammatory changes within a matter of hours.[6]

All these studies helped to evolve the rationale in support of unified airway which states;

1. Patients with upper airway diseases such as rhinitis, rhinosinusitis and polyps should have a higher prevalence of lower respiratory disease like asthma.

2. Inter-related pathophysiological mechanisms between upper airway and lower airway diseases should exist to explain interactions of these two disease processes.

3. Treatment of one portion of unified airway should improve the other.

Comorbid chronic rhinosinusitis, sinonasal polyposis and bronchial asthma are common associations. Whereas each condition represents a common independent medical problem, pulmonologists, allergists and otolaryngologists have suggested causal links between them. ${ }^{[18,7,8,]}$ One way to approach a possible causal relationship between rhinosinusitis and asthma is to demonstrate improvement in asthma after medical or surgical treatment of rhinosinusitis. Improvements in bronchial asthma were suggested, but not conclusively demonstrated, in earlier trials using aggressive medical or surgical approaches (or both) to chronic rhinosinusitis. They concluded that there is a correlation between treatment of rhinosinusitis and improvement in asthma. In one study, $79 \%$ of patients with asthma and rhinosinusitis were able to discontinue taking their bronchodilators after receiving antibiotic treatment for their rhinosinusitis. Moreover, pulmonary function tests normalised in $67 \%$ of those patients and improvement in asthma symptoms has been reported. Treatment for rhinosinusitis with antibiotics and a topical steroid spray plus a short course of oral corticosteroids have been shown to induce a decrease in IL-4 and an increase in IFN- $\gamma$ levels. $[19,20,21,9]$

During the past 4 decades, functional endoscopic sinus surgery (FESS) has been successfully used as a more physiological surgical approach to the treatment of medically refractory rhinosinusitis. The original concept of using an endoscope for surgery to normalise the ventilation and mucociliary clearance of sinuses by creating a patent outflow still holds good.[10,11,12,13] Many studies have shown symptomatic and radiographic improvement of sinus disease by FESS in as high as $90 \%$ of patients followed up to 3 years after the operation.[22]

In our study, there was a small but definite improvement in pulmonary function following endoscopic sinus surgery as evidenced by pre-and post-operative spirometric measures. Even if the surgery was indicated for the upper airway disease, the improvement in lower airway function clearly signifies the concept of unified airway as discussed earlier and signifies a decrease in the bronchial hyperresponsiveness as compared to the pre-operative condition. Furthermore, more recent studies have demonstrated the efficacy of endoscopic sinus surgery on asthmatic patients in alleviating symptoms and enhancing QOL. After endoscopic sinus surgery in patients with asthma and concomitant rhinosinusitis, there was an improvement in asthma symptoms and reductions in total dosage of steroids and in the number of days of steroid use in the first year after surgery. Moreover, there was an improvement in respiratory functions, including increased peak expiratory flow measurements and a significant decrease in bronchial hyperreactivity, after sinus surgery. About $70 \%$ of patients had less frequent asthma and $65 \%$ had less severe asthma, along with a $75 \%$ reduction in hospitalisations and an $81 \%$ reduction in acute care visits during the year after the surgery. It definitely is a clear indication that treatment for rhinosinusitis has a beneficial effect on asthma.[14,15,16,] Improved vital capacity in patients with childhood asthma in our study, within a short span post-operatively, emphasises the role of nasobronchial reflex which possibly serves as a pathological link between upper and lower airway inflammations. It is likely, however, that medical treatment used after surgery, such as oral antibiotics and oral or topical steroids, also have direct pulmonary effects.[17]

The maximum improvement in our study was observed in 
patients below 15 years and minimal in elderly. This may be attributed to age related respiratory compromise occurring in general population even without surgery. As per the study, even though female patients benefited more, it was found to be statistically insignificant. Less improvement in smokers compared to non-smokers in early postoperative period may be due to co-existing generalised airway inflammation and added ciliary damage. Medical comorbidities like diabetes mellitus and hypertension had little bearing on the outcome. So, there is no point in prioritising surgery in expectation of improved respiratory status during followup. Patients with allergic rhinitis showed considerable post-operative improvement in FEV1 and FVC. Since allergy is a fore runner of asthma, surgical alteration of allergic trigger points has a definite bearing on the improvement of overall respiratory status. Patients with Aspirin intolerance and Samter's triad are known to have extensive disease resistant to majority of the treatment modalities. These patients have the most resistant polyposis of the sinonasal region which notoriously recurs following surgery. Radiologic evaluation of the nose and paranasal sinuses revealed more extensive involvement of the sinuses in these patients and underwent a greater number of repeat operations. On average, patients with Samter's triad had undergone approximately 10 times as many previous FESS procedures as had the patients without Samter's triad. Finally, at 6 months following their most recent surgery, patients with Samter's triad had significantly higher rates of symptom recurrence (nasal obstruction, facial pain, postnasal drip, and anosmia) and a recurrence of nasal polyps.[23,24] Just like the less favourable surgical outcome in the upper airway, beneficial effects have been not been consistently reported for endoscopic sinus surgery in patients with aspirin hypersensitivity in the lower airway in alleviating asthma. $[25,26]$ However, in our study though FEV1 improvement after surgery was insignificant, there was a significant improvement of FVC even 6 months after surgery; this clearly points to the reduction of lower airway resistance and possible long term advantage for improvement in the pulmonary status in such patients.

\section{CONCLUSION}

FESS effects a small but significant improvement in lung function as evidenced by pre- and post-operative spirometric measures and should be considered early in the natural course of nasal polyposis with concomitant asthma. Patients and physicians should have clear expectations about the effects of this surgery on the course of chronic bronchial asthma since added factors like age and comorbidities can modify the outcome. The surgery should be of definite benefit in children and patients with allergic rhinitis in alleviating asthma; it may show some promise in patients with NSAID intolerance which needs further studies for validation.

\section{Acknowledgements}

The authors wish to acknowledge colleagues from Department of Pulmonary Medicine for kind referral of patients with asthma who were included in the study and for the timely help provided in spirometry.

\section{REFERENCES}

[1] Bousquet JL, Khaltaev N, Cruz AA , et al. Allergic Rhinitis and its Impact on Asthma (ARIA) 2008 update (in collaboration with the World Health Organization, GA(2)LEN and AllerGen). Allergy 2008;63(Suppl 86):8160.

[2] Virchow JC. Asthma, allergic rhinitis, sinusitis. Concept of the unified respiratory tracts. HNO 2005;53(Suppl 1):S16-S20.

[3] Krouse JH, Veling MC, Ryan MW, et al. Executive summary: Asthma and the unified airway. Otolaryngol Head and Neck Surgery 2007;136(5):699-706.

[4] Kaufman J, Chen JC, Wright GW. The effect of trigeminal resection on reflex bronchoconstriction after nasal and nasopharyngeal irritation in man. Am Rev Respir Dis 1970;101(5):768-9.

[5] Shturman-Ellstein R, Zeballos RJ, Buckley JM, et al. The beneficial effect of nasal breathing on exercise-induced bronchoconstriction. Am Rev Respir Dis 1978;118(1):65-73.

[6] Braunstahl GJ, Fokkens WJ, Overbeek SE, et al. Mucosal and systemic inflammatory changes in allergic rhinitis and asthma: a comparison between upper and lower airways. Clin Exp Allergy 2003;33(5):579-87.

[7] Dixon AE. Rhinosinusitis and asthma: the missing link. Current Opinion Pulmonary Medicine 2009;15(1):1924.

[8] Lai L, Hopp RJ, Lusk RP. Pediatric chronic sinusitis and asthma: a review. J Asthma 2006;43(10):719-25.

[9] Ragab S, Scadding GK, Lund VJ, et al. Treatment of chronic rhinosinusitis and its effects on asthma. Eur Respir J 2006;28(I):68-74.

[10] Kennedy DW, Zinreich SJ, Rosenbaum AE, et al. Functional endoscopic sinus surgery. Theory and diagnostic evaluation. Arch Otolaryngol 1985;111(9):576-82.

[11] Stammberger H. Functional endoscopic sinus surgerypart 2. Otolaryngology Head \& Neck Surgery 1986;94:15.

[12] Stamrnberger H, Posawetz W. Functional endoscopic sinus surgery. Concept, indications and results of the Messerklinger technique. Eur Arch Otolaryngology 1990;247(2):63-76.

[13] Lund VJ, Holmstrom M, Scadding GK. Functional endoscopic sinus surgery in the management of chronic rhinosinusitis: an objective assessment. J Laryngol Otol 1991;105(10):832-5.

[14] Dhong HJ, Jung YS, Chung SK, Choi DC. Effect of endoscopic sinus surgery on asthmatic patients with chronic rhinosinusitis. Otolaryngology Head and Neck Surg 2001;124(I):99-104.

[15] Uri N, Cohen-Kerem R, Barzilai G, et al. Functional endoscopic sinus surgery in the treatment of massive polyposis in asthmatic patients. J Laryngol Otol 2002;116(3):185-9.

[16] Dejima K, Hama T, Miyazaki M, et al. A clinical study of endoscopic sinus surgery for sinusitis in patients with bronchial asthma. Int Arch Allergy Immunol 2005;138(2):97-104.

[17] Ragab S, Scadding GK, Lund VJ, et al. Treatment of chronic rhinosinusitis and its effects on asthma. Eur Respir J 2006;28(I):68-74. 
[18] De Benedictis FM, Bush A. Rhinosinusitis and asthma: epiphenomenon or causal association? Chest 2009;136(5 Suppl):30.

[19] Corren J, Rachelefsky GS. Inter-relationship between sinusitis and asthma. Immunol Allergy Clin North Am 1994;14:171-183.

[20] Kim HY, Dhong HJ, Chung SK, et al. Clinical characteristics of chronic rhinosinusitis with asthma. Auris Nasus Larynx 2006;33(4):403-8.

[21] Kim YH, So KY, Dhong HJ, et al. Prevalence of lower airway diseases in patients with chronic rhinosinusitis. Acta Otolaryngologica 2007;127(Suppl 558):110-4.

[22] Poetker DM, Mendolia-Loffredo S, Smith TL. Outcomes of endoscopic sinus surgery for chronic rhinosinusitis associated with sinonasal polyposis. Am J Rhinol 2007;21(1):84-8.
[23] Amar YG, Frenkiel S, Sobol SE. Outcome analysis of endoscopic sinus surgery for chronic sinusitis in patients having Samter's triad. J Otolaryngol 2000;29(1):7-12.

[24] Kim JE, Kountakis SE. The prevalence of Samter's triad in patients undergoing functional endoscopic sinus surgery. Ear Nose Throat J 2007;86(7):396-9.

[25] Awad OG, Fasano MB, Lee JH, et al. Asthma outcomes after endoscopic sinus surgery in aspirin-tolerant versus aspirin-induced asthmatic patients. Am J Rhinol 2008;22(2):197-203.

[26] Loehrl TA, Ferre RM, Toohill RJ, et al. Long-term asthma outcomes after endoscopic sinus surgery in aspirin triad patients. Am J Otolaryngol 2006;27(3):154-60. 